\title{
Synthesis and Characterization of Photoaffinity Probes that Target the 5- $\mathrm{HT}_{3}$ Receptor
}

\author{
Thomas Jack\$, Marc-David Ruepp, Andrew J. Thompson, Oliver Mühlemann, and Martin Lochner*
}

§SCS-Metrohm Foundation Award for best oral presentation

\begin{abstract}
The $5-\mathrm{HT}_{3}$ receptor is one of several ion channels responsible for the transmission of nerve impulses in the peripheral and central nervous systems. Until now, it has been difficult to characterize transmembrane receptors with classical structural biology approaches like X-ray crystallography. The use of photoaffinity probes is an alternative approach to identify regions in the protein where small molecules bind. To this end, we present two photoaffinity probes based on granisetron, a well known antagonist of the $5-\mathrm{HT}_{3}$ receptor. These new probes show nanomolar binding affinity for the orthosteric binding site. In addition, we investigated their reactivity using irradiation experiments.
\end{abstract}

Keywords: Granisetron $\cdot 5-\mathrm{HT}_{3}$ receptor $\cdot$ Photoaffinity probes $\cdot$ Photo-labeling $\cdot$ Serotonin receptor

\section{Introduction}

In popular science serotonin is referred as a 'happiness hormone'. Also known as 5-hydroxytryptamine (5-HT), it is an important neurotransmitter that is involved in many processes in the human body such as the regulation of appetite, mood, sleep, vasoconstriction, body temperature and gastrointestinal motility. It may also be associated with disorders such as aggression, anxiety, addiction, emesis and nausea. ${ }^{[1]}$

The family of human serotonin receptors contains seven different subtypes (5$\mathrm{HT}_{1}$ to $5-\mathrm{HT}_{7}$ ) that are widely distributed throughout the body.[2] Most serotonin receptors are G-protein coupled receptors that influence the intracellular concentrations of cAMP and IP3. ${ }^{[3]}$ The only exception is the $5-\mathrm{HT}_{3}$ receptor, a ligand-gated ion channel selective for sodium and potassium ions. They are transmembrane proteins, composed of five subunits that surround an ion-conducting pore and their activation triggers a neuronal excitation by depolarization of the cell plasma membrane (Fig. 1). ${ }^{[4]}$

There are several approved drugs that selectively antagonize $5-\mathrm{HT}_{3}$ receptors and these are primarily used to treat chemotherapy-, radiotherapy- and post operativeinduced nausea and vomiting.

Binding of serotonin triggers the opening of an ion channel, but competitive antagonists like granisetron are able to block the orthosteric binding site and thereby inhibit pore opening. Until now, a high-resolution crystal structure of the 5-HT ${ }_{3}$ receptor has not been obtained and our knowledge of the binding cavity has largely been based on mutagenesis and homology with related proteins. ${ }^{[5]}$

The aim of our project is the development of photoaffinity probes that can be used to covalently modify the $5-\mathrm{HT}_{3}$ receptor, and after subsequent enzymatic diges- tion, identify the orientation of the ligand in the binding pocket by mass spectrometry (Scheme 1).

We base our probe design on the known high-affinity ligand granisetron.[6] Previous studies in our group have identified three positions where bulky groups can be introduced to the molecule without losing the binding affinity of the parent compound (Fig. 2). ${ }^{[7]}$

\section{Synthesis of Photolabile Antagonists}

Based on the structure-activity relationship studies of granisetron we introduced a photolabile diazirine at the indazole position $\mathrm{N}(1)$ and $\mathrm{C}(7)$ to obtain two final compounds $\mathbf{1}$ and $\mathbf{2}$, which were synthesized according to the procedure shown in Schemes 2-5.

The compounds $\mathbf{1}$ and $\mathbf{2}$ were assem- $\overline{{ }^{*} \text { Correspondence: }}$ Prof. Dr. M. Lochner Universität Bern

Departement für Chemie und Biochemie

Freiestrasse 3

$\mathrm{CH}-3012$ Bern

Tel.: +41316313311

E-mail: martin.lochner@dcb.unibe.ch

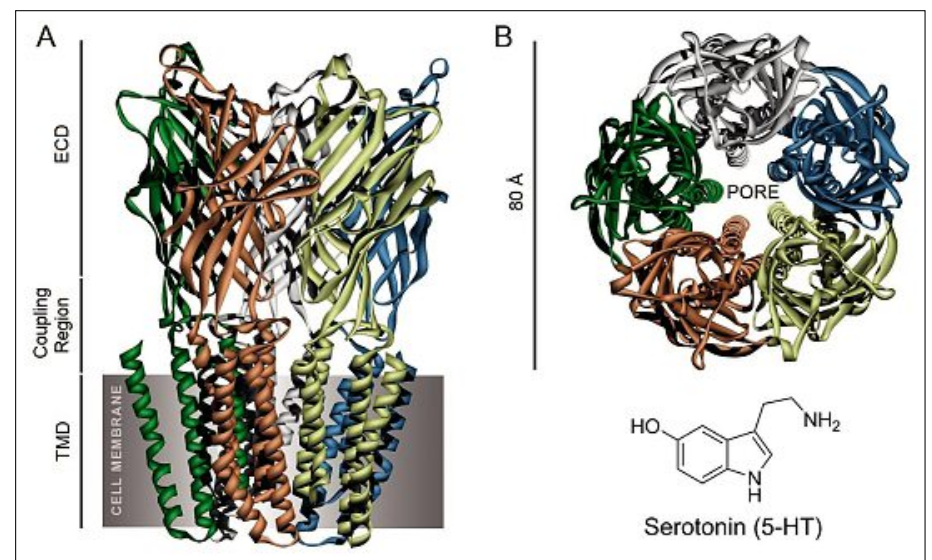

Fig. 1. Homology model of the $5-\mathrm{HT}_{3}$ receptor based on a related GLIC structure (PDB ID: 3EAM) showing the side view (A) and top view (B). 


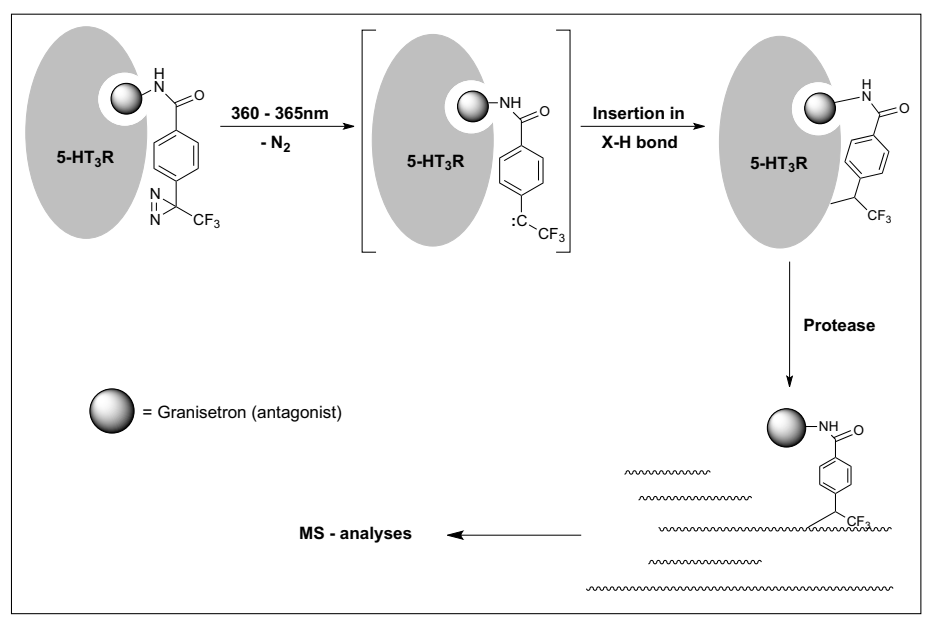

Scheme 1. Identification of binding pocket with the photolabile antagonist and mass spectrometry.

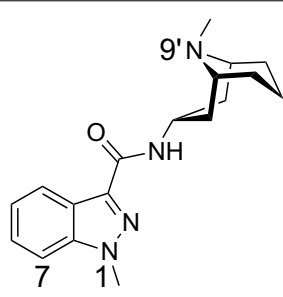

Fig. 2. Granisetron can be modified at the nitrogens $\mathrm{N}(1)$ and $\mathrm{N}\left(9^{\prime}\right)$ as well as $\mathrm{C}(7)$.

bled using a convergent synthetic strategy based on the bicyclic amine 5, an indazole core 8/9 and an aromatic diazirine acid $\mathbf{2 1}$. The bicyclic amine $\mathbf{5}$ was synthesized according to literature protocols (Scheme 2), ${ }^{[8]}$ starting from glutaraldehyde and aceton-1,3-dicarboxylic acid, which forms pseudopelletierine (3) in a Robinson tropinon-type synthesis. ${ }^{[9]}$ In this double-Mannich-decarboxylation cascade reaction bicyclic product $\mathbf{3}$ is produced in high yields $(95 \%)$. The keto group was then converted to the hydroxylamine 4 which could be reduced with $\mathrm{AlH}_{3}$ that was formed in situ from $\mathrm{LiAlH}_{4}$ and $\mathrm{H}_{2} \mathrm{SO}_{4}$, to yield endoamine $\mathbf{5}$ as a single isomer.

Primary amine 5 was coupled either to commercially available $1 H$-indazole- 3-carboxylic acid 9 (Scheme 3), which allows the modification on the $\mathrm{N}(1)$ position, or was coupled to 7-methoxy-1Hindazole-3-carboxylic acid (8), which was synthesized according to the literature, starting from 3-methoxyphenol as shown in Scheme 4. ${ }^{[10]}$

After the introduction of a TMS group and conversion of the OTMS group to a better leaving group (OTf) the indazole core was formed by a 1,3-dipolar cycloaddition of in situ generated benzyne and ethyl diazoacetate. The subsequent saponification led to $\mathbf{8}$, which could be coupled with bicyclic amine 5, to yield $\mathbf{1 0}$. The indazole nitrogen N(1) of compound $\mathbf{1 0}$ was methylated and the methoxygroup cleaved in the second step to allow further functionalization with linkers and the photoactivatable diazirine.

3-( $N$-Boc-amino)propyl bromide was used as a linker which was attached via the hydroxy group of 12, or via the indazole nitrogen $\mathrm{N}(1)$ in the case of $\mathbf{1 1}$.

The subsequent deprotection gave the amines 13 and 14 (Scheme 5) which allowed the introduction of the photolabile diazirine group that was synthesized as shown in Scheme 6.[11] Treating TBSprotected 4-bromo-phenylmethanol with

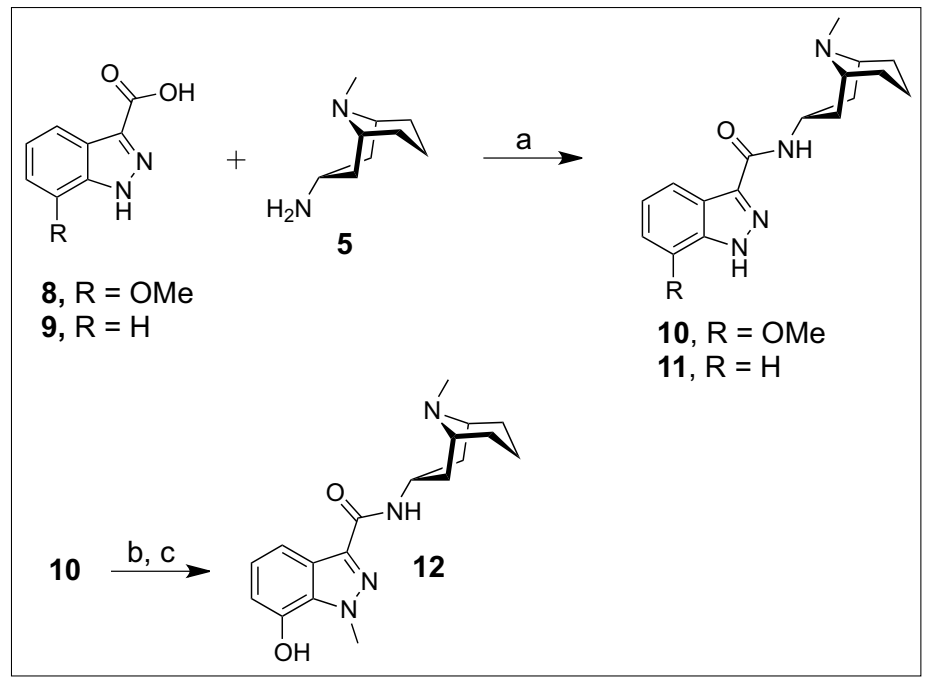

Scheme 3. Reagents and conditions: (a) $\mathrm{HOBt}, \mathrm{DCC}, \mathrm{CH}_{2} \mathrm{Cl}_{2}$, 14 h, r.t., $82 \%(8)$, quant. (9); (b) KOt-Bu, Mel, THF/DMF, 42\%; (c) $\mathrm{BBr}_{3}, \mathrm{CH}_{2} \mathrm{Cl}_{2}, 24 \mathrm{~h}$, r.t., crude.

\section{Binding Affinity}

We explored the binding properties of the two compounds $\mathbf{1}$ and $\mathbf{2}$ at the $5-\mathrm{HT}_{3}$ receptor by competition with radiolabeled $\left[{ }^{3} \mathrm{H}\right]$ granisetron. Both compounds had binding affinities in the nanomolar range, with compound 2 showing the comparably higher affinity, with a $K_{i}$ of $8 \mathrm{nM}$ compared to 1 with a $K_{i}$ of $123 \mathrm{nM}$.

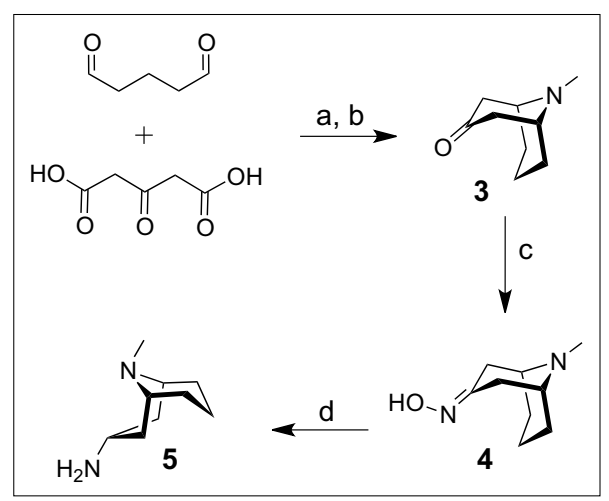

Scheme 2. Reagents and conditions: (a) $\mathrm{MeNH}_{3} \mathrm{Cl}, \mathrm{Na}_{2} \mathrm{HPO}_{4}, \mathrm{NaOH}, 20$ h, r.t.; (b) $\mathrm{HCl}$, $1 \mathrm{~h}, 100{ }^{\circ} \mathrm{C}$, for both steps: $95 \%$; (c) $\mathrm{NaOAc}$, $\mathrm{NH}_{3} \mathrm{OHCl}, 4$ h, r.t. $92 \%$; (d) $\mathrm{H}_{2} \mathrm{SO}_{4}$, $\mathrm{LiAlH}_{4}$, THF, 8 h, r.t. to $45^{\circ} \mathrm{C}, 30-92 \%$.

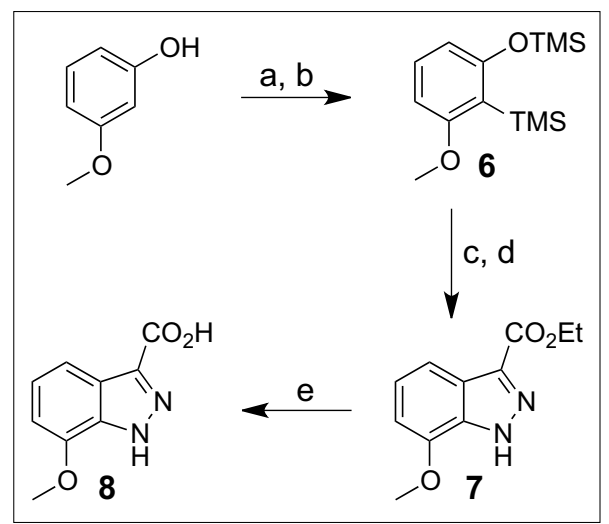

Scheme 4. Reagents and conditions: (a) HMDS $1 \mathrm{~h}, 75^{\circ} \mathrm{C}$, crude; (b) $i$ - $\mathrm{Pr}_{2} \mathrm{NH}, n$-BuLi, TMS$\mathrm{Cl}$, THF, $13 \mathrm{~h},-78^{\circ} \mathrm{C}$ to r.t., $87 \%$; (c) $n$-BuLi, $\mathrm{Tf}_{2} \mathrm{O}, \mathrm{Et}_{2} \mathrm{O}, 0^{\circ} \mathrm{C}$ to r.t., $90 \%$; (d) $\mathrm{N}_{2} \mathrm{CHCO}_{2} \mathrm{Et}$, TBAF, THF, $-78{ }^{\circ} \mathrm{C}$ to r.t., 24 h, $81 \%$; (e) $\mathrm{NaOH}$, $\mathrm{MeOH}, 14 \mathrm{~h}, 60^{\circ} \mathrm{C}$, quant. 


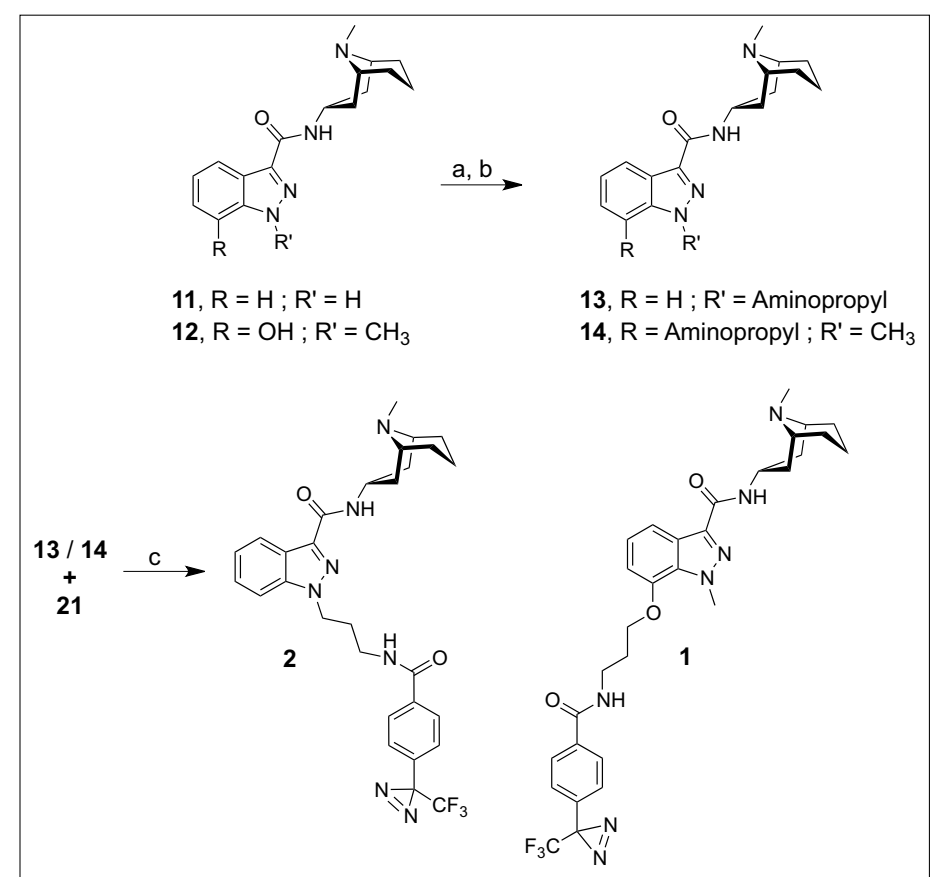

In previous studies we showed that a bulky fluorophore attached to the indazole nitrogen of granisetron was tolerated without losing the binding affinity. ${ }^{[7]}$ As compounds 1 and $\mathbf{2}$ contained two identical linker/diazirine combinations at $\mathrm{C}(7)$ and $\mathrm{N}(1)$, their binding affinities can be directly compared. The data suggest that the granisetron binding pocket is less sterically confined around the $\mathrm{N}(1)$ nitrogen and thus this position is more likely to accommodate bulky modifications. ${ }^{[12]}$

\section{Irradiation of Diazirines}

Diazirines are known to form a carbene by extruding $\mathrm{N}_{2}$ when irradiated with lowenergy wavelength light $(>300 \mathrm{~nm}){ }^{[13]}$ These long wavelengths and the ability of the newly formed highly reactive carbene to rapidly insert into $\mathrm{C}-\mathrm{H}$ or heteroatom-
Scheme 5. (a) KOt$\mathrm{Bu}, 3-(\mathrm{N}$-boc-amino) propylbromide, THF/ DMF, $14 \mathrm{~h}, 0^{\circ} \mathrm{C}$ to r.t.; (b) $\mathrm{HCl}$, dioxane, 14 h, r.t., for both steps: 70\% (13), 31\% (14); (c) $\mathrm{HATU}, \mathrm{Et}_{3} \mathrm{~N}, 24 \%$ (2), $20 \%$ (1).

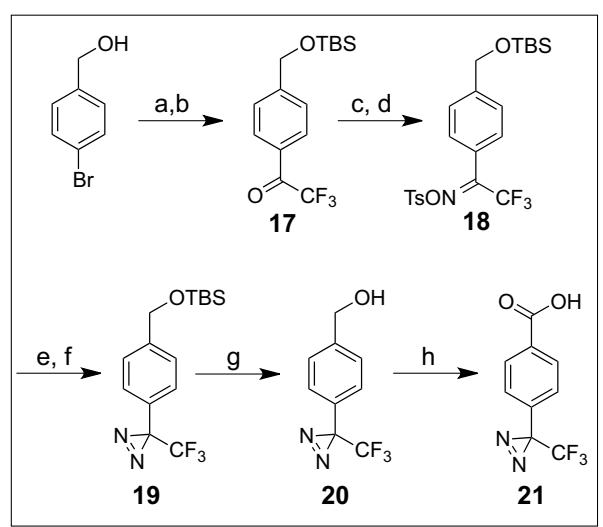

Scheme 6. Reagents and conditions: (a) TBS$\mathrm{Cl}$, imidazole, DMF, $14 \mathrm{~h}, 40^{\circ} \mathrm{C}$, quant.; (b) $n$-BuLi, diethyl-trifluoro-acetamide, $\mathrm{Et}_{2} \mathrm{O}, 4 \mathrm{~h}$, $-78{ }^{\circ} \mathrm{C}, 78 \%$; (c) hydroxylamine $\mathrm{HCl}$, Pyridine, $\mathrm{EtOH}, 4 \mathrm{~h}, 60^{\circ} \mathrm{C}$, crude; (d) TsCl, Pyridine, 3.5 h, both steps: $59 \%$; (e) $\mathrm{NH}_{3}, \mathrm{Et}_{2} \mathrm{O}, 14 \mathrm{~h},-78^{\circ} \mathrm{C}$ to r.t., $90 \%$; (f) $\mathrm{MnO}_{2}, \mathrm{CH}_{2} \mathrm{Cl}_{2}, 48$ h, r.t. $70 \%$; (g) $\mathrm{HCl}, \mathrm{MeOH} 6$ h, r.t., $53 \%$; (h) $\mathrm{KMnO}_{4}, \mathrm{KOH}$, dioxane, $2 \mathrm{~h}$, r.t., $70 \%$.

To verify the stability of diazirines in lab light conditions we exposed 3-(4-(bromomethyl)phenyl)-3-(trifluoromethyl)$3 H$-diazirine to lab light and followed its decomposition with ${ }^{19} \mathrm{~F}-\mathrm{NMR}$. First photo-decomposition (16\%) peaks similar to compounds $\mathbf{2 2}$ and $\mathbf{2 3}$ were detected after $6.5 \mathrm{~h}$ and full conversion of the diazirine was observed after $76 \mathrm{~h}$. This low reactivity allows the handling of diazirine compounds without excessive light protection. main compounds by MS, similar to those described by Hosoya and coworkers (Fig. 3). ${ }^{[15]}$ One was the insertion product $\mathbf{2 3}$ of the carbene into the $\mathrm{D}-\mathrm{O}$ bond of $\mathrm{d}_{4}$ $\mathrm{MeOD}$, and the second was the isomerized diazo compound 22 shown in Scheme 7.

We further found that irradiating the sample with shorter wavelength light (302 $\mathrm{nm}$ ) produced more insertion product $\mathbf{2 3}$ from 22, presumably through the intermediacy of the carbene. This is in agreement with similar published studies. ${ }^{[15]}$

\section{Conclusion}

We have successfully synthesized two new photoaffinity probes based on the selective and high-affinity $5-\mathrm{HT}_{3}$ receptor antagonist granisetron. The probes were tested at the human $5-\mathrm{HT}_{3}$ receptor and revealed nanomolar binding. The probes were irradiated to investigate reaction times

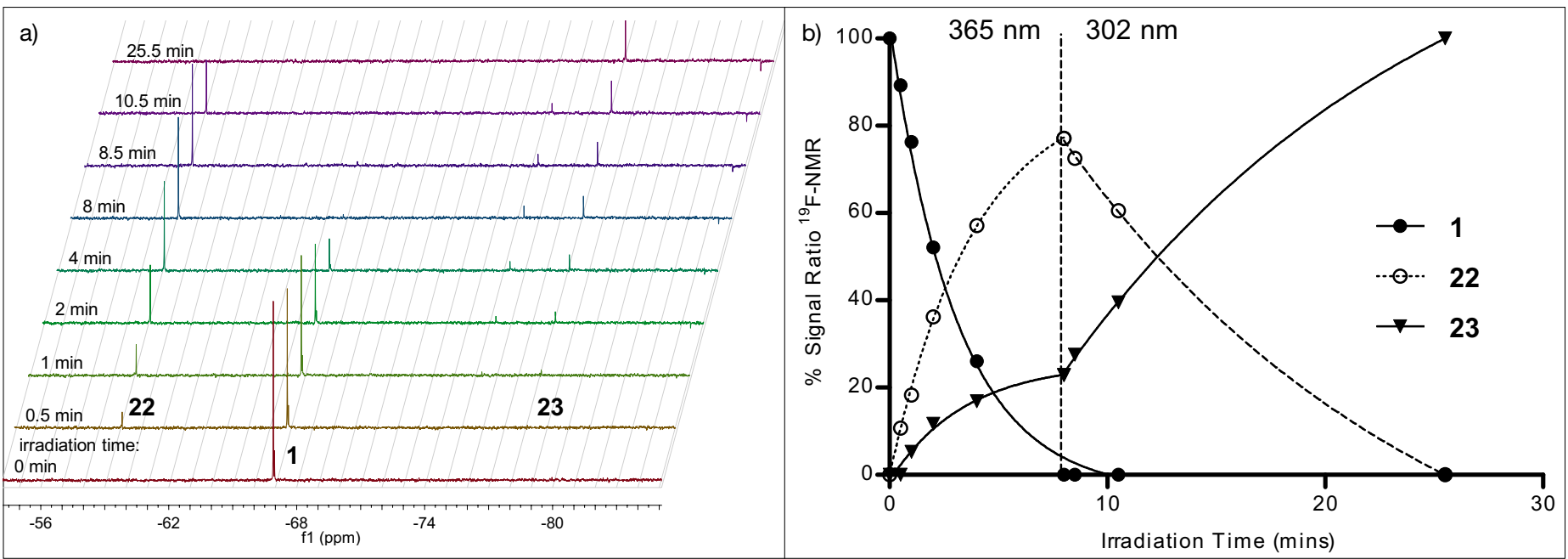

Fig. 3. a) ${ }^{19} \mathrm{~F}-\mathrm{NMR}$ of irradiated diazirine $\mathbf{1}\left(-66.9 \mathrm{ppm}\right.$ ) (irradiation: $8 \mathrm{~min}$ at $365 \mathrm{~nm}$, then $17.5 \mathrm{~min}$ at $302 \mathrm{~nm}$ ) b) ${ }^{19} \mathrm{~F}-\mathrm{NMR}$ signal ratio of compound $\mathbf{1}$ to the two main decomposition products over irradiation time. 


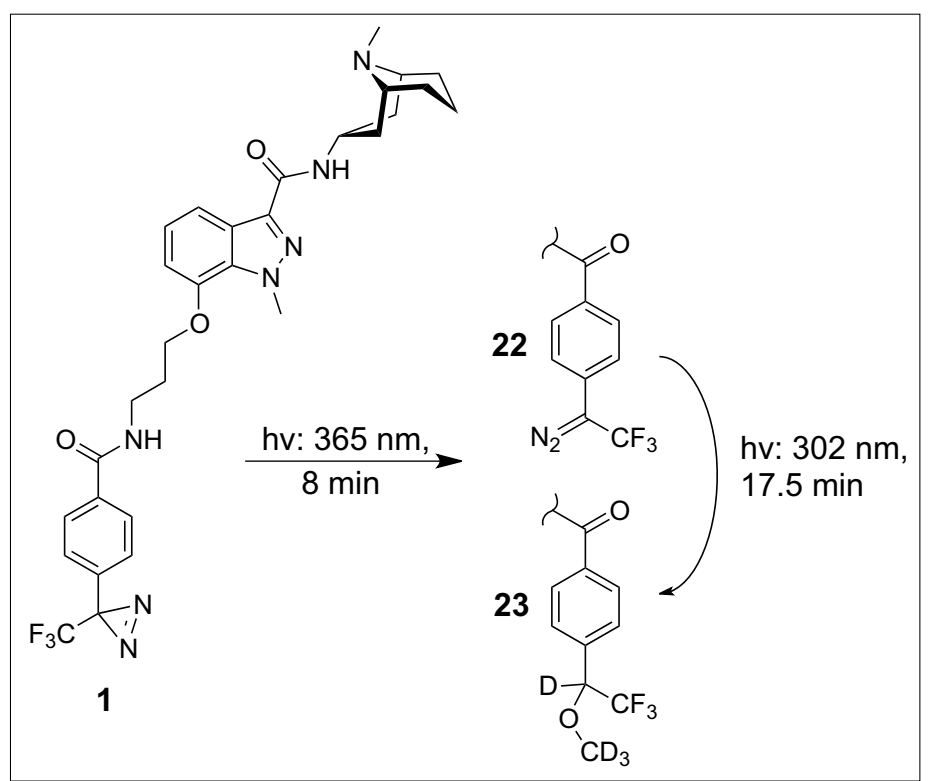

Scheme 7.

Photoreaction of $\mathbf{1 .}$

for further experiments in receptor labeling and showed a high reactivity at long wavelength irradiation. This makes them useful tools for investigating the $5-\mathrm{HT}_{3}$ receptor binding site, by photocrosslinking the probes with the receptor and subsequent digestion. The resulting fragments will be analyzed by mass spectrometry and, in conjunction with homology models and mutagenesis data, will help to identify the position and orientation of the probes in the receptor binding pocket. These experiments are part of our ongoing efforts to develop fluorescent and bioorthogonal molecular tools for the investigation of transmembrane proteins, including ligandgated ion channels (hERG), G-protein coupled receptors (adenosine receptors) and transporters (high-affinity glutamate transporters and TRPV channels).

\section{Acknowledgements}

The authors would like to thank Dr. Michele Leuenberger for support and many fruitful discussions. Metrohm AG and the Swiss Chemical Society are gratefully acknowledged for the award. This work was supported by the Swiss National Science Foundation (SNSFprofessorship PP00P2_123536 to M. L.). M.-D. R. was supported by a SNSF Sinergia grant (CRSII3-136222 to O.M.).

Received: January 16, 2014
[1] A. J. Thompson, S. C. Lummis, Expert Opin. Ther. Targets 2007, 11, 527 .

[2] J. Walstab, G. Rappold, B. Niesler, Pharmacol. Ther. 2010, 128, 146.

[3] a) M. Pytliak, V. V. V. Mechírová, M. Felšöci, Physiol. Res. 2011, 60, 15; b) D. Hoyer, J. P. Hannon, G. R. Martin, Pharmacol. Biochem. Behav. 2002, 71, 533; c) M. Berger, J. A. Gray, B. L. Roth, Annu. Rev. Med. 2009, 60, 355.

[4] N. M. Barnes, T. G Hales, S. C. R. Lummis, J. A. Peters, Neuropharmacol. 2009, 56, 273.

[5] A. J. Thompson, H. A. Lester, S. C. R. Lummis, Quart. Rev. Biophys. 2010, 43, 449.

[6] A. J. Thompson, S. C. R. Lummis, Curr. Pharm. Des. 2006, 12, 3615.

[7] S. K. V.Vernekar, H. Y. Hallaq, G. Clarkson, A. J. Thompson, L. Silvestri, S. C. R. Lummis, M. Lochner, J. Med. Chem. 2010, 53, 2324.

[8] O. Dold, K. Stach, W. Schaumann, US Patent Appl. No. 3.509.161, 1970.

[9] R. Robinson, J. Chem. Soc., Trans. 1917, 111, 762.

[10] Z. Liu, F. Shi, P. D. G. Martinez, C. Raminelli, R. C. Larock, J. Org. Chem. 2008, 73, 219.

[11] a) L. B. Shih, H. Bayley, Anal. Biochem. 1985, 144, 132; b) J. H. Robson, J. Reinhart, J. Am. Chem. Soc. 1955, 77, 498; c) M. Nassal, Liebigs Ann. 1983, 9, 1510.

[12] D. Kesters, A. J. Thompson, M. Brams, R. van Elk, R. Spurny, M. Geitmann, J. M. Villalgordo, A. Guskov, U. H. Danielson, S. C. R. Lummis, A. B. Smit, C. Ulens, EMBO Rep 2013, 14, 49.

[13] L. Dubinsky, B. P. Krom, M. M. Meijler, Bioorg. Med. Chem. 2012, 20, 554.

[14] A. Singh, E. R. Thornton, F. H. Westheimer $J$. Biol. Chem. 1962, 237, 3006.

[15] T. Hiramatsu, Y. Guo, T. Hosoya, Org. Biomol. Chem. 2007, 5, 2916. 